\title{
Erratum
}

\section{Protocatechuic acid induces cell death in HepG2 hepatocellular carcinoma cells through a c-Jun $\mathbf{N}$-terminal kinase-dependent mechanism}

\author{
E.C.H. Yip ${ }^{1}$, A.S.L. Chan ${ }^{1}$, H. Pang ${ }^{1}$, Y.K. Tam ${ }^{2}$ and Y.H. Wong ${ }^{1}$ \\ ${ }^{1}$ Department of Biochemistry, the Molecular Neuroscience Center, and the Biotechnology Research \\ Institute, Hong Kong University of Science and Technology, Clear Water Bay, Kowloon, Hong Kong, \\ China; ${ }^{2}$ Novokin Biotech Inc., Edmonton, Alberta, Canada
}

Cell Biology and Toxicology. 2006;22(4):293-302.

The corresponding author of this article is Y.H. Wong (boyung@ust.hk), not E.C.H. Yip. 